\title{
Lessons in fisheries politics
}

\author{
Gerry Kristianson \\ Sport Fishing Advisory Board, Canada \\ E-mail address: gerrykr@telus.net.
}

This is the accepted manuscript of an article published in Fisheries Research. The final version may be accessed at https://doi.org/10.1016/i.fishres.2018.03.025.

\begin{abstract}
Advocates for recreational fishing, public servants charged with fisheries management, and scientists and other experts who provide objective advice, all need to understand the nature and dimensions of fisheries politics.
\end{abstract}

Accusing someone of "playing politics" usually is intended as a criticism, even an insult. But politics is the social process by which differences are expressed and resolved. If you don't have differences, then you don't have politics. A political situation, whether it is in a family, the workplace, government administration or a contest for public office is the process through which differences are discussed and settled.

Fisheries politics takes place at many levels. It determines the resources available to manage fisheries and understand their impacts. It defines the relationship between conservation and extraction. It determines the allocation of harvest between competing interests. It sets the international rules between nations for the conservation and sharing of migratory and straddling stocks.

Underlying these political relationships are rules and norms of political behavior that can be learned and practised by those who wish to maximize their influence over how fisheries are managed and practised.

Canada's West Coast provides a useful example of efforts by the Canadian government to facilitate fisheries politics by providing structures and processes within which different interests can contribute to the politics of fisheries management. A participant-observer brings his perspective as both an ardent angler and a political scientist specializing in the relationship between interest groups and government to suggest some rules for effective engagement in fisheries politics.

Accusing someone of "playing politics" usually is intended as a criticism, even an insult. But this usage overlooks the fact that politics simply is the social process by which differences are expressed and resolved. If you don't have differences, then you don't have politics. A political situation, whether it is in a family, the workplace, government administration or a contest for public office should be the civilized means by which differences can be discussed and settled. 
The future of recreational fishing in Canada and elsewhere will be determined by the ability and willingness of its participants and their supporters to engage in politics. It is inevitable that there will be arguments around the methods and results of fisheries science. There always will be debate about how to measure and set conservation levels. Conflict over access between competing groups of harvesters and between their respective national jurisdictions is unavoidable and there is obvious tension between anglers and those who believe sport fishing constitutes unethical treatment of animals. It is essential to the future of recreational fishing that there be meaningful processes in which these kinds of differences can be discussed and hopefully resolved.

\section{Effective politics needs sensible and sensitive representative entities and processes}

There are useful lessons to be learned from efforts in the Pacific Region of Canada's Department of Fisheries and Oceans to provide structures and processes within which fisheries politics can be played out. Both elected officials and public servants have been sensitive to the need to hear from those affected by their decisions. They have demonstrated this sensitivity by supporting development of representative organizations and by maintaining a complex array of advisory bodies within which diverse interests can play a role in fisheries management.

These efforts deserve full credit. Regardless of partisan changes in ministers and governments, on the West Coast the department has attempted to ensure that its constituents are heard from in a consistent way. This is not to suggest perfection either in process or outcome. Nor is this example necessarily capable of replication elsewhere. As a social process, politics needs to accommodate itself to local circumstances. What works on Canada's West Coast may not be transferable elsewhere in our diverse federal country, let alone to other jurisdictions. But as a long-time participant in fisheries politics and as a political scientist whose academic specialization has been the relationship between private interests and government, I think there are helpful lessons to be learned from this example.

DFO has facilitated and encouraged the creation of a series of representative entities for harvesters on the West Coast. In many respects, this process started with creation of the Sport Fishing Advisory Board (SFAB) in 1964 when anglers saw their access to chinook and coho salmon being undermined by a preoccupation with the interests of commercial harvesters. The department reacted to the demands of anglers by facilitating creation of a common table with representatives of a diverse array of recreational organizations and individuals. It has since supported the growth or creation of similar entities to represent the interests of commercial and indigenous harvesters as well as to give voice to non-harvest interests preoccupied with conservation.

The SFAB provides a useful example from the perspective of recreational fishing. The current geographic structure is based on 23 committees in local communities. Elected chairs then represent their members on either a North or South Coast Regional Committee, which in turn 
sends representatives to a Main Board. Between Main Board meetings, an executive of ten members acts on behalf of the sector.

An important aspect of the SFAB structure is the requirement that at all levels a decisionmaking majority rest with what are defined as "primary" members, anglers who do not have a vested economic interest in the fishery, as distinct from representation of "secondary" interests which derive economic benefit as service providers to the fishery. This is reflected explicitly through designated seats at all three levels to both primary and secondary organizational members. As two key examples, the British Columbia Wildlife Federation with its local fish and game clubs is the largest primary organization while the Sport Fishing Institute is the industry association for fishing lodges, charter boat operators and tackle manufacturers.

DFO gives explicit support to the SFAB process by covering the travel expenses of its volunteer participants.

\section{Effective politics needs intersectoral advisory institutions}

Having facilitated and supported the creation of an array of entities representing the interests of harvesters and conservationists, DFO also has established a series of processes within which these interests can provide management advice on different fisheries. In each of these advisory bodies the department provides logistical support and in some cases travel expenses for volunteer participants. These bodies comprise a lengthy list, examples being the Salmon Integrated Harvest Planning Committee, the Halibut Advisory Board, the Groundfish Integrated Advisory Board, the Tuna Advisory Board, the Sardine Advisory Board, the Prawn Advisory Board and the Crab Intersectoral Advisory Board.

The recreational fishery perspective on each of these bodies is put forward by representatives chosen by the SFAB. As an example, the Salmon IHPC has two regional components, for the North and South Coasts. On both, the SFAB has three representatives and alternates, who share the table with commercial, Aboriginal and Marine Conservation Caucus representatives. Since their terms of reference encourage most of the advisory committees is to give consensus advice whenever possible, voting numbers are not an issue. When consensus is not possible, the rules dictate the need for officials to carefully document any differences and ensure these are reflected in advice to the Minister.

One complexity in the operation of these advisory processes has been how to include representation from the indigenous community in circumstances where individual First Nations assert a constitutional right to government-to-government relations with Canada and its provinces and territories. When First Nations meet separately with department officials to the exclusion of others it creates at least the perception that the interests of recreational and commercial harvesters might be neglected. 


\section{International politics}

DFO also has recognized the need to ensure that the interests of its diverse constituencies are reflected at the international level. The Pacific Salmon Commission was created in 1985 to assist the Canadian and US governments in managing the conservation and harvest of five species of anadromous fish that originate in the two countries but are vulnerable to mixed stock interception and harvest.

The Commission has been structured to ensure that harvesters from both countries are represented on a series of geographic panels. These panels in turn give advice to four commissioners and four alternates from each country.

Another example of this effort to ensure political representation of harvester interests at the international level is the International Pacific Halibut Commission. In this case, three commissioners from each country are provided with advice by a bilateral panel of processors and by a Conference Board in which aboriginal, recreational and commercial harvesters from both countries meet annually to try and reach agreement or at least consensus on the development of harvest policy.

\section{The politics of science and protected areas}

While some scientists might like to pretend that "politics" has no relevance to their "objective" conclusions and the work behind it, the reality is that the scientific method of using experimentation and observation to answer questions in a rigorous way is all about the resolution of differences. In other words, science has its own politics.

In Canada, this reality has been recognized through the structure of the Canadian Science Advisory Process (CSAP) which includes harvester and conservationist representatives in the peer review process by which scientific findings are considered before being incorporated into advice to management.

Similarly, under Canada's Species at Risk legislation, the process for listing threatened or endangered species includes the opportunity for input from affected interests. A recent example is a request for input on whether to list Boccacio, a groundfish species, as endangered. This was circulated widely to the department's advisory bodies. Having been provided with links to the relevant background material, people were told that an online public consultation period would be active September 7-December 8, 2017 and that an online survey was open for comment. This sort of consultation was an important part of the process leading to the endangered listing of Southern Resident killer whales, which has now entered the phase where internet-based consultation on possible recovery measures is being followed by a public symposium.

A similar political process is being applied by Canada to the development of Marine Protected Areas as part of efforts to give credence to its international conservation commitments. As an example, the rules for designation of an MPA for unique Glass Sponge Reefs in Hecate Strait, 
initially were developed by a working group from the department's Groundfish Integrated Advisory Board (GIAB). The consensus recommendation of that body was later undermined by an internet-based lobbying campaign and the department currently is wrestling with how to reconcile consensus advice from its advisory bodies with contradictory efforts taking advantage of new communications technology.

Another recent example of DFO's efforts to manage the politics around creation of protected areas is the creation of a series of MPA Network Ocean Advisory Committees with representation of all affected interests.

\section{Conclusion: four key rules of fisheries politics}

As a self-described "fisheries politician" I would like to conclude these comments on how fisheries politics plays out in my jurisdiction by offering some observations based on many years as a participant in fisheries management activity, sometimes as an advocate for domestic recreational angling interests but also as a representative of Canada's broader fishery interests at meetings of the Pacific Salmon Commission, the North Pacific Anadromous Fish Commission and the International Pacific Halibut Commission.

\section{The resource must come first}

Whether the discussion is domestic or international, my first rule of effective fisheries politics is to remember that the resource must always come first. The debate must be about ensuring sustainable fish stocks, not arguing about who gets to harvest the last fish. Anglers, like all other harvesters, must be conscientious participants in the collection of catch data so that there can be effective stock assessment. Recreational catch statistics must pass the "red face" test as must an accurate understanding of the impact of angler encounters on fish that are not retained. Government fisheries managers, competing harvesters, and other interested parties must be satisfied with the accuracy of recreational numbers. While there will be differences in the way data is collected about the impact of hundreds of thousands of individual anglers as distinct from much smaller numbers of commercial vessels, there must be trust in the numbers.

In the case of British Columbia this need can be demonstrated by the fisheries for salmon and halibut.

- In the case of salmon, Canadian government policy has given recreational anglers priority over commercial harvesters in access to chinook and coho. But this precedence needs to take account of aboriginal priority to harvest for food, social and ceremonial purposes, as well as the obligations that go with international management of these highly migratory species. It is obvious that there can be no agreement that these varied needs are being met unless there is common trust in the statistics on recreational impact.

- With respect to Pacific Halibut, Canada's access to this migratory species is subject to international management, and the country's portion (after aboriginal priority) is shared between recreational and commercial harvesters on a $15 \%-85 \%$ basis. Not only must 
angling catch statistics be accurate enough to ensure that the sector does not overfish Canada's share, but data is needed to plan fishing rules that effectively ration a million pounds of highly sought-after fish amongst 100,000 or so anglers in circumstances where GPS technology, in particular, has increased angler efficiency. Both the long-term sustainability of the resource and the recreational sector's self interest dictate that accurate data be available!

\section{Science is important - but must be understandable}

A second rule of effective fisheries politics is to remember that while knowledge is essential to good management, the basis of scientific advice must be clear, understandable and relevant. Anglers (and other harvesters) have a right to demand that jargon be kept to a minimum. It helps, when confronted by yet another set of numbers whose accuracy is being justified because the Bayesian statistical approach was applied, to remind the speaker that after his death in 1761, the Reverend Thomas Bayes' comments on solving the problem of inverse probability were used as the basis for proving the existence of God!

It also needs to be said that anglers can and should participate directly in science through things like DNA collection and the maintenance of detailed catch logbooks. Our local "Avid Anglers" program has been developed in direct co-operation with current and retired DFO scientists. Anglers have undertaken the systematic collection and recording of samples during their fishing trips and been rewarded both by new knowledge about the fish they have encountered and by evidence that the information they have collected can have a direct bearing on better management of harvest.

An issue that has arisen in Canada is the attempt by government to divert from taxpayers some of the cost of fisheries science by a policy called the "Use of Fish" whereby a portion of the total allowable catch is designated to cover the costs of such things as stock assessment. The problem for the recreational sector is that with species like salmon and halibut, the economic and social value of an individual fish greatly exceeds the profit margin available after commercial harvest. It makes more sense to require anglers to make a direct contribution toward the costs of catch monitoring and stock assessment through a licence fee rather than by foregoing catch so that it can be harvested commercially and the margin above cost diverted to these purposes.

\section{Politics is about people: civility is key}

Politics is a human social process. Since its purpose is the resolution of differences between people it should not be surprising that civility is a key component. Treating others as you expect to be treated seems a simple maxim, yet frequently forgotten when politics devolves into ideological position-taking or when commonly held prejudices or preconceptions result in the pejorative description of other participants. Demonizing other groups of harvesters isn't conducive to reaching intersectoral consensus on fisheries management. Demeaning the role of conscientious public servants by disparaging them as "bureaucrats" isn't likely to earn their trust or support. I choose to call myself a "Fisheries Politician" as a way of making clear to 
elected officials that I think politics is a noble calling and admire those who have chosen to put themselves forward for election and thereby are best able to claim they represent the public interest. It is their role to adjudicate between those of us who in a plural society have both a right and an obligation to advance our private interests through reasoned civil discourse.

\section{Murphy is always around}

Finally, it needs to be understood that politics, as a human social activity, is subject to circumstances that cannot always be controlled or predicted. The adage frequently cited as "Murphy's Law" applies. If things can go wrong they usually will. An important lesson for anyone attempting to organize anglers as part of a campaign to influence fisheries management decisions is that many of the potential participants would rather be fishing! 